\title{
Heterosexismo y homofobia en la novela latinoamericana de tema homosexual
}

\author{
Heterosexism and Homophobia in \\ Latin American Homosexual Novel
}

\author{
Heterosexismo e homofobia no romance \\ latinoamericano de temática homosexual
}

Darío Gómez-Sánchez ${ }^{1}$

\author{
Resumen
}

Partiendo de los planteamientos de Michel Foucault sobre identidad sexual, se realiza una lectura comparativa de un conjunto de novelas latinoameric anas publicadas a lo largo del siglo pasado y protagonizadas por personajes 'homosexuales' con el objetivo de analizar la elaboración literaria de tal identidad. El artículo se ocupa en demostrar que estas novelas reiteran el discurso dicotómico heterosexualidad-homosexualidad y, con este, reproducen la ideología que considera inferiores o anormales las prácticas sexuales intermasculinas. En el análisis se destacan algunas constantes narrativas que contribuyen con esta reproducción, como la ausencia de cuestionamiento de la homofobia institucional o personal, el egocentrismo discursivo de los personajes principales, la recurrencia a estereotipos de masculinidad y feminidad y, consecuentemente, al machismo y la misoginia. Se concluye que lo que finalmente se representa en estas novelas son los mecanismos de exclusión y discriminación de los sujetos de tales prácticas, contribuyendo así a la perpetuación de la homofobia y el heterosexismo dominantes.

\section{Palabras clave}

identidad homosexual; literatura gay; novela latinoamericana; teoría queer; heterosexismo; homofobia

\section{Abstract}

Based on Michel Foucault's views on sexual identity, this paper provides a comparative reading of a group of Latin American novels published over the last century and featuring "homosexual" characters, with the purpose of analyzing the literary development of such identity. The paper shows that these novels reiterate the dichotomous discourse of heterosexuality-homosexuality and, thus, reproduce the ideology that sees sexual practices between men as inferior or abnormal. The analysis highlights some narrative constants that contribute to this, such as the lack of questioning of institutional or personal homophobia, the discursive egocentrism of the main characters, the use of stereotypes of masculinity and femininity and, therefore, sexism and misogyny. It is concluded that what is ultimately represented in these novels are the mechanisms of exclusion and discrimination of the subjects of such practices, thus contributing to the perpetuation of dominant homophobia and heterosexism.

\section{Keywords}

homosexual identity; gay literature; latin american novel; queer theory; heterosexism; homophobia

\section{Resumo}

A partir das abordagens de Michel Foucault sobre identidade sexual, realiza-se uma leitura comparativa de um conjunto de romances latino-americanos publicados ao longo do século anterior e protagonizadas por personagens homossexuais visando analisar a elaboração literária dessa identidade. 0 artigo procura demonstrar que esses romances reiteram o discurso dicotômico heterossexualidade-homossexualidade e, com ele, reproduzem a ideologia que considera inferiores ou anormais as práticas sexuais inter-masculinas. $\mathrm{Na}$ análise sobressaem alguns elementos narrativos que contribuem com essa reprodução, como a ausência de questionamento da homofobia institucional ou pessoal, o egocentrismo discursivo dos personagens principais, os estereótipos de masculinidade e feminidade e, consequentemente, o machismo e a misoginia. Em conclusão, o que é finalmente representado nesses romances são os mecanismos de exclusão e discriminação dos sujeitos dessas práticas, contribuindo assim à perpetuação da homofobia e o heterossexismo dominante.

\section{Palavras chave}

identidade homossexual; literatura gay; romance latino-americano; teoria queer, heterossexismo; homofobia

Artículo recibido el 1 de noviembre de 2016 y aprobado el 28 de julio de 2017

1 Doctor en Literatura Comparada de la Universidad Federal de Rio de Janeiro. Profesor adjunto del Departamento de Letras de la Universidad Federal de Pernambuco, Recife, Brasil. Contacto: dario.sanchez@ufpe.br 


\section{Planteamiento}

A partir de las elaboraciones de Foucault en su Historia de la sexualidad, diversos estudiosos coinciden en afirmar que la diferenciación de los sujetos por su sexo, género o deseo sexual no es más que una forma de control sociocultural:

La idea de Foucault de que la homosexualidad reciente está presente a partir de 1870 , por más históricamente cuestionable que sea, ha representado un giro crucial y probablemente irreversible de nuestro pensamiento: al afirmar su contingencia histórica, nos convida a cuestionar todo el sistema de oposición binaria de género del que la homosexualidad es apenas un término [...] Homosexual-heterosexual, masculinidadfeminidad, hombre-mujer: según muchos piensan hoy, la única manera apropiada de pensar esas categorías es buscar sus determinantes culturales. (Bersani, 1998, p. 49).

Y tal vez ha sido en el campo de la crítica feminista en donde el cuestionamiento de las categorías de sexo/género ha alcanzado mayor desarrollo:

La crítica feminista también debe comprender como la categoría de las "mujeres", el sujeto de lo femenino, es producida y reprimida por las mismas estructuras de poder por medio de las cuales se busca la emancipación [...] Obviamente, la tarea no es rechazar la política representacional -como si pudiésemos hacerlo. Las estructuras jurídicas del lenguaje y de la política constituyen el campo contemporáneo del poder; consecuentemente, no hay posición por fuera de ese campo, sino solamente una genealogía crítica de sus propias prácticas de legitimación. (Butler, 2003. pp. 19, 22).

Las afirmaciones de Butler se pueden aplicar literalmente a la categoría de sujeto homosexual, igualmente producido y reprimido por las estructuras de la política y del lenguaje -también de la literatura- que ratifican la existencia de tal identidad. Aunque es necesario reconocer el valor de las teorías identitarias en el proceso de conquista de algunos derechos civiles para los denominados homosexuales -como en el caso de la subcultura gay-, también es necesario realizar una "genealogía crítica" de tales teorías. Es precisamente en función de ese objetivo que nos proponemos demostrar cómo la presencia y reproducción de las diversas categorías históricas relacionadas con la definición de la identidad homosexual acaban contribuyendo, no a la denuncia sino a la ratificación de los prejuicios que favorecen la discriminación de los homosexuales dentro de un corpus de novelas latinoamericanas escritas y publicadas a lo largo de un siglo ${ }^{2}$.

Hipotéticamente, al buscar hacer visibles las características de las prácticas sexuales intermasculinas en el contexto latinoamericano, las novelas de temática homosexual contribuirían a la oposición o resistencia a un sistema que ha condenado a la marginalización y al anonimato esa opción sexual. Sin embargo, no es eso lo que ocurre, pues si bien es cierto que en algunos casos esas novelas ponen en evidencia situaciones de discriminación sexual, el eje de la intención narrativa nunca es la denuncia de los fundamentos de esa discriminación. Esto ocurre porque tales novelas representan, en sus argumentos, las definiciones psicosociales del sujeto homosexual, razón por la cual acaban validando los discursos identitarios y, con ellos, el sistema que legitima la discriminación por orientación sexual. En ese sentido, es posible afirmar que la novela latinoamericana reproduce contenidos heterosexistas en la caracterización de los personajes homosexuales.

A propósito de la relación entre las categorías identitarias y el heteroseximo, afirma Daniel Borillo (2001):

El pensamiento diferencialista aparece así como substrato ideológico de una cierta manera de producir sujetos cuya identidad sexuada y sexual se articula alrededor de las categorías hombre/ mujer y hetero/homo. Estas categorías no son

2 Las novelas que sirven de base para nuestra reflexión son: Bom Crioulo (1895) de Adolfo Caminha (Brasil), Hombres sin mujer (1935) de Carlos Montenegro (Cuba), Orgia (1968) de Tulio Carella (Argentina/Brasil), Arturo la estrella más brillante (1971) de Reinaldo Arenas (Cuba), El beso de la mujer araña (1974) de Manuel Puig (Argentina), El vampiro de la colonia Roma (1977) de Luis Zapata (México), Stella Manhattan (1985) de Silviano Santiago (Brasil), Onde andará Dulce Veiga? (1990) de Caio Fernado Abreu (Brasil), La virgen de los sicarios (1994) de Fernando Vallejo (Colombia), y Tengo miedo torero (2001) de Pedro Lemebel (Chile). 
autónomas ni mucho menos inocentes, la una no existe sino en función de la otra y por negación de su contrario. Ser un hombre es ante todo y en principio no ser una mujer, y ser un heterosexual implica necesariamente no ser un homosexual [...] Fenómeno global, a la vez cognitivo y normativo, el heterosexismo presupone la diferenciación elemental entre los grupos homos/heteros reservando sistemáticamente a este último un tratamiento preferencial. El heterosexismo es a la homofobia lo que el sexismo es a la misoginia, si es que no se confunden, ya que uno no puede concebirse independientemente de la otra. (p. 35).

Sin duda, cualquier diferenciación que hace del sexo/género/deseo un factor definidor de identidad es discriminatoria y reproductora del discurso heterosexista, pues el presupuesto básico sobre el cual tal discurso se fundamenta es que, natural y culturalmente, la heterosexualidad tiene un estatuto socio-comportamental de superioridad. Desde esa perspectiva, es posible afirmar que las novelas latinoamericanas de temática homosexual cumplen una función sociocultural que podría denominarse ideológica, en el sentido de que está más dirigida a la promoción de un conjunto de valores y creencias relacionados con un tipo de identidad sexo-afectiva particular. En otras palabras, al representar las prácticas sexuales entre hombres dentro de un contexto histórico determinado, lo que finalmente se representa son los discursos que reflexionan sobre esas prácticas $\mathrm{y}$, con ellos, la ideología que las considera inferiores o anormales; esto porque al reproducir diversas concepciones identitarias también se reproducen las formas de exclusión de una minoría denominada homosexual dentro de una sociedad que se asume como predominantemente heterosexual.

A partir de la anterior fundamentación, en las siguientes líneas vamos a ocuparnos de visibilizar algunas manifestaciones narrativas de lo que Daniel Borillo (2001) define como "el sistema a partir del cual una sociedad organiza un tratamiento segregacionista dependiendo de la orientación sexual" (p. 24), y de una de sus consecuencias más notables que es la "hostilidad general, psicológica y social, con respecto a aquellos y a aquellas de quienes se supone que desean individuos de su propio sexo o tienen prácticas sexuales con ellos" (p. 36). Más concretamente, vamos a tratar de la presencia del heterosexismo y de la homofobia en las novelas latinoamericanas de temática homosexual.

\section{Heterosexismo institucional y ausencia de denuncia}

En varias novelas latinoamericanas de temática homosexual encontramos situaciones de condena institucional a la homosexualidad, entendiendo aquí por instituciones estructuras sociales tales como el Estado, la Familia o la Iglesia, que cumplen un papel fundamental en la difusión y conservación del discurso heterosexista. Una evidencia de esa condena se encuentra en los organismos de seguridad y control gubernamental que aparecen de manera recurrente en las novelas.

En Bom-Crioulo de Adolfo Caminha, por ejemplo, encontramos varias referencias a la presencia de prácticas homosexuales dentro de la Marina. Casi al comienzo de la novela el protagonista sufre un castigo porque se supone que golpeó a un segunda clase que maltrató al joven grumete Aleixo, pero el narrador advierte que Aleixo es "um belo marinheirito de olhos azuis, muito querido por todos e de quem diziam-se 'coisas"' (p. 22), y Amaro confirma que el verdadero motivo de la golpiza es su deseo:

... Reconhecia que fizera mal, que devia ser punido, que era tão bom quanto os outros, mas, que diabo! estava satisfeito: mostrara ainda uma vez que era homem [...]

Depois estimava o grumete e tinha certeza de o conquistar inteiramente, como se conquista uma mulher formosa, uma terra virgem, um pais de ouro [...] Estava satisfeitíssimo! (Caminha, 2003, p. 23).

La satisfacción de Amaro no está motivada por una oposición consciente al código de la Marina que indirectamente censura su deseo (y en cuyo caso la intención del relato se podría entender como crítica), sino por la certeza de que ese castigo va a facilitar la conquista del delicado adolescente, hecho que de algún modo ratifica la hipótesis 
"médica" de la época sobre la perversión/inversión y según la cual la presencia del invertido motiva los instintos degenerativos del pervertido. Por eso, más que confirmar que la homosexualidad y su censura están presentes en la institución de la Marina, lo que nos interesa es evidenciar que esa condena o censura acaba siendo justificada por la novela en su totalidad, especialmente con el proceso de degeneración progresiva que sufre Amaro, producto de sus "anormales" deseos.

La presencia y censura de las prácticas homosexuales dentro de la institución militar también aparecen, aunque brevemente, en Tengo miedo torero, solo que esta vez el homosexual no se presenta como un pervertido, sino como invertido o afeminado que pone en riesgo la masculinidad de los demás soldados:

¿Cómo se les ocurre dejar entrar estos raros a la escuela militar? ¿En qué cabeza cabe permitir que un maricón use el uniforme de cadete? $¿$ No sabe usted que estos desviados son iguales que los comunistas, una verdadera plaga, donde hay uno... ligerito convence a otro y así, en poco tiempo, el Ejército va a parecer una casa de putas. ¿Y qué hacemos con él, mi General? ¡Sáquelo inmediatamente de aquí y lo da de baja! No soporto verlo mariconeando en mi jardín, insolentando a los muchachos de la escolta. (Lemebel, 2002, p. 157).

Ese "no soporto verlo mariconeando en mi jardín", pronunciado por el General se puede relacionar con la idea sintetizada por Borillo (2001) de que "la violencia contra los homosexuales no es sino la manifestación del odio hacia uno mismo o, mejor dicho, contra la parte homosexual de uno mismo que se querría hacer desparecer" (p. 103), y que en el caso de la homofobia militar equivaldría a intentar borrar un hecho que hace parte del funcionamiento institucional: la existencia de prácticas homosexuales entre sus miembros, evidenciada en la novela de Lemebel con el juego entre el cadete y el escolta, en la obra de Caminha con las "calumnias" proferidas por los marineros, y también en el relato de Reinaldo Arenas de los furtivos encuentros sexuales entre soldados y "maricas". Pero el desarrollo del asunto en Tengo miedo torero es tan reducido que no daría para afirmar que hay una crítica a la doble moral de las instituciones castrenses. Sin embargo, no deja de ser significativo el hecho de que el General exija expulsar solo al "pájaro afeminado" y no al escolta “joven y gallardo" que lo está acompañando. Aquí es importante resaltar que en la novela de Lemebel se reproduce la concepción de la relación sexual entre hombres en las condiciones de la oposición activo/ pasivo, según la cual la calificación de "homosexual" solo afecta al pasivo, que es siempre un sujeto afeminado; razón por la cual cualquier posible intención crítica o irónica sobre la homofobia militar queda oscurecida por la reproducción acrítica y reductora de la representación afeminada del sujeto homosexual.

Se observa, entonces, que presentar la discriminación por la opción sexual como tópico narrativo no implica, necesariamente, cuestionar o criticar su existencia, a menos que se denuncien los fundamentos y prejuicios que la sustentan. En Arturo, la estrella más brillante son bastante frecuentes las manifestaciones castrenses de homofobia, como en el siguiente trecho: “ ¡Ni un paso atrás! ¡Donde sea y como sea! ¡Duro con los blandengues y los mariquitas!" (Arenas, 1984, p. 46); o en este otro: “... ya no se les trataba como a seres humanos, no les ponemos la bandera, les decían los oficiales, porque ustedes no son dignos de ella" (p. 42). De hecho, la homofobia como práctica institucional del régimen revolucionario cubano es un motivo central de la novela de Arenas; no solo del argumento, sino también del paratexto, como en la nota final que narra el fusilamiento del poeta Nelson Rodríguez que había estado "internado en uno de los campos de concentración para homosexuales" (p. 93). Sin embargo, la intención primordial del narrador en Arturo, la estrella más brillante no es denunciar esa homofobia, sino presentar la fantasía y la muerte como únicas posibilidades de evasión ante el deterioro progresivo de un sistema que, entre otras cosas, persigue a los homosexuales. Más que con la denuncia es con la renuncia, más que con la crítica es con el sacrificio del individuo como, finalmente, acaba imponiéndose el discurso heterosexista. 
Es indiscutible que la referencia narrativa a la discriminación sufrida por los homosexuales en la marina brasilera, en el ejército chileno o en la Revolución cubana implica algún nivel de denuncia o crítica de la homofobia castrense, pero también es un hecho que en las novelas referidas nunca se cuestionan los fundamentos "médicos" o "antropológicos" que permiten esa discriminación, con lo que se acaba favoreciendo su reproducción. La cuestión no es diferente con relación al desarrollo narrativo de otras homofobias institucionales, como la policial en $\mathrm{El}$ beso de la mujer araña (que culmina con el asesinato de Molina), la familiar en Stella Manhattan (cuya consecuencia es la muerte de Eduardo) o la religiosa en La virgen de los sicarios (aunque en esta novela el tono anarquista del narrador permita entrever una posición más crítica), y es precisamente esa ausencia de una revisión crítica y creativa de los fundamentos de la homofobia lo que acaba favoreciendo la reproducción del discurso heterosexista en la novela de temática homosexual, pues al no problematizar ni cuestionar el origen de la condena institucional de las prácticas homosexuales, se refuerzan implícitamente los presupuestos que la legitiman.

Una afirmación como esta puede parecer extrema para los militantes gays que buscan inferir de los "chismes" de los marineros en Caminha una demostración de la ambigüedad sexual en la Marina, de la sutil escena descrita por Lemebel una ironía de la homofobia castrense, o del dolor de Arturo (y de Arenas) la denuncia de los abusos sexistas del régimen revolucionario. Mas considero que siendo la homofobia una hostilidad explícita contra las prácticas homosexuales, esa homofobia se reproduce o legitima en la medida en que ni los personajes ni el narrador la cuestionan o la ponen directamente en entredicho, que es lo que finalmente sucede en las novelas referidas.

\section{Homofobia interiorizada y egocentrismo discursivo}

Independientemente de la polémica discusión sobre su posible función transgresora, una cosa que nos llama la atención en las novelas de temática homosexual es la frecuente valoración negativa que los personajes protagonistas tienen de su personalidad en general y, particularmente, de su sexualidad. Un ejemplo de ese autorrechazo es Pascasio, protagonista de Hombres sin mujer, que se empeña en luchar contra su deseo cuando se da cuenta de que está apasionado por Andrés:

Pero, por más que hacía, por más que pensaba en el vértigo que le arrebató hasta aquellas alturas nunca soñadas, no cabía duda de que su emoción era de turbio origen. Sentado en el rincón se abrazaba a sus rodillas, oprimiéndoselas; cada minuto que pasaba lo empobrecía más y más... Entonces, todo ¿no había sido más que eso?... ¿Aquel vértigo no fue otra cosa que rodar hacia el abismo lleno de fango que lo cazaba desde el día en que puso sus pies en el presidio? Por un instante quiso defender su ilusión, que ya se había convertido en un trapo sucio -semejante a aquellos que de vez en cuando se encontraba antes, detrás de las casas pobres del pueblo, y que sirvieran para atajar sangrazas de menstruos. Él mismo no era otra cosa que un trapo sucio más [...]. (Montenegro, 1934, p. 138).

Y es ese "vértigo" de "turbio origen" el que va a desencadenar el trágico final de la novela con el suicidio de Pascasio y el asesinato de Andrés, de manera semejante al final de Bom Crioulo, cuando Aleixo es asesinado por Amaro, quien inicialmente también lucha contra su deseo. Otro ejemplo de autorrechazo por el deseo homosexual, aunque con consecuencias menos trágicas, es la confusa personalidad de Lucio Ginarte, el protagonista de Orgia, envuelto en interminables racionalizaciones de culpa y religiosidad.

Creio ser religioso, mas me arrependo ambiguamente, de maneira superficial, nunca por completo e a fundo. A carne me domina, eu sei, e não quero ser hipócrita com Deus. Não. Só me examino, vejo que não estou disposto a abandonar os prazeres da carne. Posso abandonar tudo o mais: comodidade, limpeza, leitura, filosofia, posição social. Que tem a carne que tanto atrai? Busca-se a si mesma num ato narcisista - mesmo nos heterossexuais - em vez de buscar a Deus, que é tão diferente. (Carella, 1968, p. 320). 
Carella, o mejor, el profesor Ginarte, permanece todo el tiempo buscando explicaciones que justifiquen sus prácticas homosexuales, intentando liberarse de la culpa que lo acosa, la cual, finalmente, se transforma en depresión y aislamiento. Ese rechazo del propio deseo se puede relacionar con lo que se conoce como homofobia interiorizada $\mathrm{u}$ homosexualidad egodistónica, caracterizada por la culpa, el autorrechazo y diversos conflictos emocionales como producto de una aceptación problemática de la condición homosexual. A propósito del asunto, Daniel Borillo (2001) afirma:

En una sociedad en la que los ideales sexuales y afectivos están conformados sobre la base de la superioridad psíquica y cultural de la heterosexualidad, parece difícil eludir los conflictos interiores resultantes de una falta de adecuación a tales valores. Además, los gays y lesbianas crecen en un entorno que muestra ampliamente su hostilidad antihomosexual. La interiorización de esa violencia, manifestada en forma de insultos, injurias, palabras despectivas, condenas morales o actitudes compasivas, lleva a muchos homosexuales a luchar contra sus deseos, provocando a veces conflictos psicológicos graves. (p. 108).

Inicialmente podría pensarse que esa homofobia interiorizada sería característica de los protagonistas de las novelas de comienzos del siglo $\mathrm{xx}$, en las que predomina una intención moralizante. Sin embargo, también está presente en la configuración de los personajes de las novelas que presentan una visión supuestamente menos prejuiciosa de la homosexualidad. Así, por ejemplo, sufren depresiones relacionadas con su identidad sexual los protagonistas de El vampiro de la colonia Roma y Onde andará Dulce Veiga, el primero más próximo al paradigma gay y el segundo dentro de una tendencia queer que nunca asume una identidad (homo)sexual. También la depresión se vuelve un rasgo definitorio en la personalidad del protagonista de El beso de la mujer araña, cuyo mayor recuerdo, más allá de su madre, es el de un mesero casado que conoció hace tres años y que nunca aceptó tener nada con él, y de Stella Manhattan, que intenta suicidarse después de que sus padres descubren su homosexualidad. En esta última novela se evidencia la relación directa entre la homosexualidad egodistónica y las diversas manifestaciones de la homofobia institucional (estatal, policial y familiar), especialmente en el trágico desenlace que ocurre en un calabozo de Nueva York:

Feito o exame do corpo do delito, constatou-se que, antes do suicídio presumível, ele [Eduardo] foi violentado pelos ocupantes da cela, com requintes de sadismo, isso porque, a pesar de ter sido encontrado vestido, sua roupa intima estava manchada de esperma e sangue. $O$ exame do corpo justificou essa conclusão. Acredita-se - na falta de cooperação das testemunhas oculares e possíveis criminosos - que tenha batido a cabeça contra a parede, como um louco. (Santiago, 1991, p. 259).

Mas, quedándonos por ahora en la identificación de la homofobia interiorizada, una de sus manifestaciones más evidentes es el desprecio que los homosexuales sienten por otros homosexuales, manifestación presente en algunas de las novelas. En Hombres sin mujer, por ejemplo, muchos de los personajes "sodomitas" aparecen la mayor parte del tiempo mofándose de los demás presos por sus prácticas sexuales, y en la novela de Arenas, Arturo lamenta frecuentemente tener algo que ver con sus compañeros de "género":

... gestos mudos, conversaciones inútiles, ademanes equívocos, cuerpos que eran ya animales sin habla, histéricos escarceos, libidinosos chillidos, poses y giros afectados que no tocan fondo, risita ahogada o confuso aullido, todos hundiéndose, perdiéndose, dejándose esclavizar, sin poder protestar, dejándose utilizar. (Arenas, 1984, p. 39).

El autorrechazo transferido a otros homosexuales va a hacer que en las novelas destacadas no aparezcan personajes colectivos, o mejor, una identidad grupal; de ahí la soledad que caracteriza a la mayoría de los protagonistas. No solo no encontramos ninguna muestra de identidad o posición grupal sobre la condición marginal de los homosexuales, sino que ni siquiera encontramos un ejemplo de amistad sólida entre ellos. Molina ofrece una explicación al respecto:

Sí, pero mira, mis amigos han sido siempre... putazos, como yo, y nosotros entre nosotros, ¿cómo decirte?, no nos tenemos demasiada confianza, 
porque nos sabemos muy... miedosos, flojos. Y siempre lo que estamos esperando... es la amistad, o lo que sea, de alguien más serio, de un hombre, claro. Y eso nunca puede ser, porque un hombre... lo que quiere es una mujer. (Puig, 2007, p. 178).

En Stella Manhattan, aunque la novela transcurra en un contexto de luchas políticas en que los personajes, como brasileros exilados, mantienen una constante comunicación entre sí, al final esa comunicación y ese contexto se transforman en falta de solidaridad con Eduardo, pues lo primordial para los demás es mantener su anonimato político y sexual en un país extranjero. Exceptuando "la loca de enfrente" que visita a sus amigas para presentarles a Carlos, $y$ el gramático pederasta acompañado por los sicarios adolescentes, nuestros personajes no tienen amigos ni cuentan con apoyo grupal en ningún momento: Amaro y Pascasio, Ginarte y Arturo, Molina y Eduardo, Adonis y el periodista están solos, y uno de los motivos centrales de esa soledad es la homofobia proyectada en los que son como ellos.

Sin embargo, más importante que ejemplificar diversas manifestaciones de homofobia interiorizada en el argumento de las obras, tales como el autorrechazo, la depresión y la soledad, es evidenciar el hecho de que el desarrollo narrativo de esa homofobia acaba fortaleciendo el discurso de superioridad heterosexual mediante la recurrencia a una caracterización egocéntrica de los personajes homosexuales, que aparecen configurados como sujetos cuyas ocupaciones y preocupaciones están relacionadas exclusivamente con la búsqueda de la satisfacción de su deseo sexual.

En Arturo, la estrella más brillante, la inquietud inicial del personaje de dar cuenta del abuso cede espacio ante la preparación del escenario para la llegada del adolescente imaginado. En El vampiro de la colonia Roma, desde el comienzo, el énfasis recae en el relato del surgimiento, el desarrollo y la consolidación de profesión de prostituto masculino. En Orgia el narrador-personaje relaciona todas sus actividades con el deseo permanente de encuentros sexuales; y en Onde andará Dulce Veiga? el solitario periodista relaciona casi todos sus encuentros cotidianos con el recuerdo de su única aventura homosexual. La única preocupación de esos personajes es el Yo, con un énfasis especial sobre lo sexual, lo que refuerza la percepción de que en esas novelas el contexto histórico funciona como un telón de fondo y no como el polo de un conflicto entre el sistema excluyente y el homosexual excluido. Ejemplo paradigmático de ese egocentrismo contextualizado son los comentarios del narrador-protagonista de La virgen de los sicarios, ocupado en dar cuenta de la crisis sociopolítica de una sociedad, pero siempre apareciendo él mismo como el eje y la preocupación central:

Hoy [el presidente] dando parte a la nación porque veinticinco mil soldados habían dado de baja al presunto capo-jefe del narcotráfico, contratador de sicarios. Que no prevalecería el delito, como si el delito con sus hermanos contratos no le pisara la cola. Y que vamos en la dirección correcta: "in the right direction", como oyó decir en inglés. Y yo solo pregunto una cosa: ¿la ley en Colombia matando presuntos? Ah, y que les va a dar el parte de la victoria a los gringos en su lengua, porque también él es poliglota. Y lo creo muy capaz: les lee el discurso que le escribieron en inglés con esa vocecita chillona, montañera, maricona, suya, y con el candor y acento de un niño de escuela que está aprendiendo: "This is my nose. That is your pipi". "Apaga a ese bobo marica -le dije a Alexis-, que pa maricas los de aquí adentro!" Se rio de verme tan desquiciado, tan enojado, y oh milagro, lo apagó. Y añadió: "Si querés te quiebro a esa gonorrea", con esos calificativos suyos que adoro. (Vallejo, 2002, pp. 47-48).

Es evidente que la narración en primera persona favorece el discurso egocéntrico, relacionado con la homofobia interiorizada en la medida en que muchas veces refleja la angustia causada por la identidad homosexual, pero en las novelas dialogadas y/o en tercera persona tampoco es muy diferente: ejemplos de ello son los largos monólogos de El beso de la mujer araña, no solo aquellos en que Molina narra filmes que revelan sus fantasías románticas, sino también aquellos en que el autor presenta, en notas de pie de página, las teorías psicoanalíticas sobre la homosexualidad. También en Bom Crioulo y Hombres sin mujer, aunque la narración omnisciente y el énfasis naturalista en la descripción de los ambientes atenúen las preocupaciones exclusivamente personales, 
también es cierto que el carácter biográfico y el recurso de la omnisciencia selectiva acaban reforzando ese egocentrismo discursivo del que hablamos.

La exacerbada angustia narcisista de los personajes (y de los narradores) de la mayor parte de las novelas de temática homosexual, como manifestación de una homofobia interiorizada, acaba haciendo de muchas de ellas algo monótono y repetitivo: "Yo soy un homosexual (o me gusta tener sexo con hombres), y eso determina lo que pienso, hago o dejo de hacer y, primordialmente, aquello por lo que sufro y hablo", esa parece ser la afirmación fundamental de muchos de los protagonistas de las novelas analizadas. El problema está en que esa excesiva y casi siempre angustiante preocupación por la propia sexualidad acaba favoreciendo la confirmación de los estereotipos socioculturales con los cuales el discurso heterosexista justifica la exclusión de las prácticas sexuales intermasculinas.

\section{Estereotipos heterosexistas}

Al encuadrar el deseo sexual intermasculino dentro de las teorías de la identidad homosexual y, en consecuencia, en la caracterización de esa identidad como una anormalidad, las novelas referidas acaban validando la idea de que existe un grupo de sujetos con características psico-biológicas y/o socio-comportamentales específicas que permiten su reconocimiento, contribuyendo así a la conformación, confirmación y re-producción de diversos estereotipos heterosexistas $y$, en consecuencia, de la homofobia.

Peter Fry (1983) afirma que la homosexualidad, así como la feminidad y la masculinidad, es una creación sociocultural, y que los llamados "homosexuales" son presionados a desempeñar diversos roles sociales y a asumir estereotipos reforzados de diversas maneras y por diversos discursos, como el científico o el antropológico, y los relatos que reproducen la idea de una identidad homosexual. Solo en virtud de esa reproducción discursiva se explica la presencia recurrente de personajes estereotipados como el hombre (negro) pervertido y el adolescente (rubio) invertido, el bisexual (intelectual) confundido o el (revolucionario) activo y el (artesano) pasivo.
Es por eso que afirmamos que la novela de temática homosexual va mucho más allá del registro narrativo de las prácticas sexuales intermasculinas y de las teorías de la identidad que las categorizan, hasta llegar a una re-producción de los argumentos del discurso heterosexista. Esta reproducción se lleva a cabo de diversas maneras, entre las cuales se destacan la promoción de los estereotipos del hombre superior, de la mujer inferior y del homosexual negativo.

\section{Caracterización negativa}

En relación directa con la homofobia interiorizada y el discurso egocéntrico, está el énfasis frecuente de los narradores y/o personajes en una especie de angustia existencial como trazo común a la personalidad del homosexual. Los protagonistas de las novelas destacadas aparecen como sujetos infelices, sacrificados, incomprendidos y atormentados: Amaro y Pascasio sufren inicialmente por la naturaleza de su deseo y después por los celos inevitables; Ginarte evidencia la angustia producida por la soledad y por sus múltiples encuentros sexuales; Arturo, Molina y Eduardo profundizan emocionalmente su condición de víctimas hasta el punto en que parecen encontrar placer en ella; $y$ finalmente el periodista de Abreu y el gramático de Vallejo se dedican al juzgamiento de los otros para reforzar sus insatisfacciones personales. La infelicidad parece ser, para todos ellos, un hecho inevitable y, en muchos casos, la consecuencia ineludible de sus deseos sexuales. A propósito del discurso homofóbico, Daniel Borillo (2001) afirma:

Cuando se deja atrás la hostilidad, el discurso homófobo no puede impedir el adquirir un tono paternalista. Como en otros tiempos respecto de las mujeres, aún hoy en relación con los niños o los discapacitados, se intenta colocar a los homosexuales bajo una especie de vigilancia protectora, tratándoles como inferiores [...] En esos casos, la desigualdad de trato de que son víctimas los homosexuales se justifica por un mecanismo de negación que consiste en ocultar las prácticas discriminatorias y poner el acento en la idea de una "deficiencia estructural" de los dominados. Esta última puede referirse a los trazos psicológicos 
atribuidos a los homosexuales, tales como el narcisismo, la incapacidad afectiva y el no reconocimiento de la alteridad, productos de un estancamiento en la evolución normal del aparto psíquico. (p. 38).

Es ese énfasis en la incapacidad de amar y ser feliz como rasgo de la personalidad que permite hablar, no simplemente de una homosexualidad egodistónica como característica de los personajes, sino también de la re-producción de un discurso homofóbico como implicación ideológica de esas novelas, discurso homofóbico que se refuerza con la idea de la violencia como condición contextual o natural de la identidad homosexual. De hecho, varios personajes de las novelas son violentos por "su naturaleza". Amaro, por ejemplo, antes de conocer a Aleixo,

\begin{abstract}
Armava-se de navalha, ia para os cais, todo transfigurado, os olhos dardejando fogo, o boné de um lado, a camisa aberta num desleixo de louco, e então era um risco, uma temeridade alguém aproximarse dele. $O$ negro parecia uma fera desencarcerada: fazia todo mundo fugir, marinheiros e homens de praia, porque ninguém estava para sofrer uma agressão... Quando havia conflito no cais Pharoux, já toda a gente sabia que era o Bom-Crioulo. (Caminha, 2003, p. 22).
\end{abstract}

Y en esa caracterización inicial del personaje se anticipa la tragedia final de la novela, de manera semejante a lo que sucede con la caracterización violenta y el desenlace trágico de Pascasio en Hombres sin mujer.

Advierte Borillo (2001): "Así como los extranjeros, los homosexuales, por sus 'prácticas extrañas', son sospechosos de amenazar la cohesión cultural y moral de la sociedad. El discurso homófobo hace de ese fantasma punta de lanza de su combate" (p. 37). De ahí que, si no son violentos los personajes homosexuales, son violentas las situaciones con las cuales aparecen relacionados: Molina, la mujer araña, está preso por abuso sexual de un menor de edad; Stella/ Eduardo se suicida o muere asesinado, así como Arturo, la estrella brillante; y el gramático que enamora adolescentes acaba justificando los crímenes que cometen sus amantes. Tal vez sea Tengo miedo torero la única novela que no se adapta a este modelo de negativismo, violencia e infelicidad. Allí no encontramos manifestaciones de abuso debidas a la orientación sexual (aunque esté presente la homofobia militar y familiar, pero como asuntos secundarios). El personaje principal pocas veces se lamenta de su condición y vivencia con humor la imposibilidad de su relación con Carlos, que culmina en una sólida amistad. Excepción hecha de la obra de Lemebel, las de temática homosexual son novelas caracterizadas por el abuso y la violencia y, principalmente, por la recurrencia a la angustia como rasgo definidor de la identidad de sus personajes, y con eso reafirman el estereotipo cultural del homosexual como un sujeto atormentado. Obviamente, también es posible encontrar algunas características positivas atribuidas a esos personajes, como la disciplina y la lealtad, además de la capacidad de desempeñarse bien en lo que cada uno de ellos hace. No obstante, esas características vienen siempre acompañadas de un sentido negativo: Amaro es un excelente marinero, pero solo hasta el momento en que conoce a Alejo; Pascasio es un hombre cabal, pero solo hasta cuando encuentra a Andrés; Lucio es un excelente profesor, pero tiene una vida doble que compromete su competencia; Molina es un óptimo decorador de vitrinas, pero fue acusado de intimidar a un menor de edad; Arturo dedica todo su potencial creativo al servicio de sus fantasías erótico-afectivas; Eduardo pierde su bienestar familiar y laboral por causa de su sexualidad; "La loca de enfrente" deja de hacer manteles para colaborar con la causa de Carlos; las capacidades periodísticas de quien busca a Veiga se ven reducidas por sus recuerdos de Pedro, y las dotes de gramático de Fernando no valen nada frente al encantador analfabetismo de sus amantes. O sea, cuando existen, las cualidades de esos personajes se ven reducidas, anuladas o invalidadas por su sexualidad.

\section{Misoginia homosexual}

A propósito de los estereotipos, Esperanza Bosch (1999) afirma:

Podemos considerar los estereotipos como un caso especial de categorización. Es decir, a partir de una serie de variables físicas (sexo, raza, edad...) y/o sociales (pertenencia a un grupo 
político, religioso...) asignamos a las personas a grupos y organizaciones la información disponible sobre ellas. Como resultado de ese proceso de categorización, las personas tendemos a: a) la asimilación, es decir, a minimizar las diferencias intragrupales, percibiendo a los miembros de un grupo como más iguales entre sí de lo que realmente son; y $b$ ) al contraste, es decir, a aumentar las diferencias intergrupales, percibiendo las diferencias entre los grupos como mayores de lo que realmente son. (p. 138).

De la categorización por asimilación podría ser ejemplo aquella afirmación implícitamente reproducida por las novelas según la cual el homosexual es un sujeto infeliz o atormentado, $y$ en un sentido más general, la idea de que el deseo de relaciones sexuales intermasculinas define un tipo de identidad particular, denominada sujeto homosexual.

De la categorización o constitución de estereotipos por contraste el mejor ejemplo es la afirmación de la superioridad de los hombres sobre la inferioridad de las mujeres y de los homosexuales. Lo curioso es observar que la misoginia, como manifestación sexista equivalente a la homofobia heterosexista, está presente en varias de las novelas referidas, y contribuye así a la constitución de los prejuicios de género -de los mismos prejuicios de que son víctimas frecuentes los homosexuales-y para la reproducción de la idea de una supuesta superioridad masculina, según la cual serían los hombres los biológica e históricamente responsables por el dominio de la cultura y de la sociedad.

No es mi interés tratar de las complejas motivaciones psicológicas que determinan la percepción que los denominados homosexuales tendrían de las mujeres -entre las cuales ocuparía un lugar muy interesante el fenómeno del travestismo-, sino apenas detenerme en la caracterización que de ellas se hace en las novelas con el objetivo de determinar hasta dónde su tratamiento es estereotipado o discriminatorio y, en consecuencia, reproductor de un paradigma (hetero)sexista del cual los homosexuales también son víctimas. De hecho, entendiendo la misoginia como una aversión manifiesta con relación a la mujer sustentada en una supuesta superioridad masculina, es posible encontrar en las novelas referidas algunos momentos en los cuales la mujer aparece subestimada, juzgada o caricaturizada por los personajes homosexuales.

Paradójicamente, una forma recurrente de representación de la mujer en las novelas de homosexuales es por su ausencia como personaje, al punto que varias de estas se pueden calificar como universos exclusivamente masculinos; este es el caso de $L a$ virgen de los sicarios, o de Hombres sin mujer, en la última de las cuales la falta de contacto con mujeres determina, según insiste el narrador, la aparición de prácticas sexuales entre los presidiarios, cosa que también ocurre entre soldados y homosexuales presos en Arturo, la estrella más brillante. Mas esa ausencia de mujeres es solo física, pues ellas están presentes como una referencia constante, y negativa en la mayoría de los casos: en el argumento de Arenas el recuerdo de la madre sirve para explicar los traumas del personaje, en la novela de Montenegro se habla de las traiciones de las esposas de los presidiarios y en el relato de Vallejo las mujeres, procreadoras, son catalogadas como seres realmente indeseables:

Cuentan que poco antes de mi regreso a Medellín pasó por esta ciudad destornillada un loco que iba inyectando en los buses cianuro a cuanta perra humana embarazada encontraba y a sus retoños. ¿Un loco? ¿Llamáis "loco" a un santo? ¡Desventurados! Dejádmelo conocer para darle más de lo dicho y un diploma al mérito que lo acredite como miembro activo de la orden del santo rey. Ah, y una buena dosis de jeringas desechables, no se le vayan a infectar sus pacientes. (Vallejo, 2002, p. 146).

La referencia a la mujer ausente como causante de males sociales y personales se suma a la presencia de la mujer carente que procura en el hombre la posibilidad de satisfacer sus necesidades afectivas o sexuales. En Stella Manhattan encontramos un personaje femenino que busca sexo en la calle con hombres desconocidos; en El vampiro de la colonia Roma se hacen algunas referencias a la madrina que, a falta de hijos, ayuda económicamente al protagonista ofreciéndole dinero y buscándole empleo; en Orgia se cuenta la historia de una estudiante que, asustada por la proximidad de su matrimonio, 
decide perder su virginidad con el profesor Ginarte; y en Tengo miedo torero, la frívola enamorada de Carlos intenta todo el tiempo controlarlo. Es también notable esa caracterización de la mujer como un ser carente en la portuguesa dueña de la pensión, que acaba quitándole Alejo a Bom-Crioulo:

- Pr'aí meu jasmim de estufa, pr’aí. Vais conhecer uma portuguesa velha de sangue quente. Deixa a inocência pro lado, vamos!...

Bateu a porta e começou a se despir a toda pressa, diante de Aleixo, enquanto ele se deixava estar imóvel, muito admirado para essa mujer-homem que o queria deflorar ali assim, torpemente, como um animal.

- Anda meu tolinho, despe-te também: aprende com tua velha... Anda, que eu estou nem uma brasa!...

Aleixo não tinha tempo de coordenar idéias. D. Carolina o absorvia, transfigurando-se a seus olhos.

Ela, de ordinário tão meiga, tão comedida, tão escrupulosa mesmo, aparecia-lhe agora como um animal formidável, cheio de sensualidade, como uma vaca do campo extraordinariamente excitada, que se atira ao macho antes que ele prepare o bote...

Era incrível aquilo! A mulher só faltava urrar! (Caminha, 2003, p. 68).

En la novela de Manuel Puig la mujer asume un papel muy importante, pues aunque no sea un personaje "real", su presencia va más allá del recuerdo o de la aparición esporádica para convertirse en un punto de referencia fundamental, sugerido desde el título. Las mujeres en Puig aparecen como protagonistas de los filmes, reales e imaginarios, que Molina le relata a Valentín. Jóvenes o viejas, elegantes u ordinarias, fuertes o sumisas, todas ellas parecen tener algo en común: la capacidad de sacrificarse por su hombre, del mismo modo que ocurre con el protagonista de la novela.

Es posible que ese paralelo entre el actuar de la mujer y del homosexual en El beso de la mujer araña sea menos una evidencia de (hetero)sexismo que una crítica a la supuesta superioridad masculina, que podría ser puesta en entredicho por la relación de dependencia establecida, pero incluso en este caso, tanto las mujeres de los filmes como el homosexual de la novela aparecen definidos en función del personaje masculino, que es finalmente quien otorga sentido a su acción. Tal vez sea posible encontrar un sentido crítico para la visión estereotipada de la mujer (pero no del homosexual) en la novela de Lemebel, en la que el personaje de la esposa del dictador es caracterizada mediante el recurso de la ironía:

¿No crees que deberías mandar a construir una capilla en el lugar del atentado? Porque no pensarás vestirte de café por seis meses como los cabros chicos cuando hacen una manda. Aunque con ese uniforme plomo parece que siempre anduvieran de manda. ¿Nunca se te ha ocurrido Augusto, que los uniformes podrían ser de distinto color para cada estación del año? Sí, ya sé que estás pensando que soy frívola, se verían tan lindos los chicos con trajes de color sandía en verano... (Lemebel, 2002, p. 202)

Sin embargo, creemos que en Tengo miedo torero el frecuente contraste entre la difícil situación sociopolítica que enfrenta el General y las preocupaciones "estéticas" de su esposa funciona más como una crítica de las veleidades del poder que de la frivolidad atribuida a la mujer en una cultura heterosexista. Tanto en la novela de Puig como en la de Lemebel, en lugar de una supuesta evidencia crítica de la misoginia, lo que aparece finalmente es la reproducción más o menos directa de la idea de la inferioridad femenina.

En síntesis, y casi sin excepción, la mujer como personaje, presente o referido, aparece caracterizada como abusadora, carente y/o frívola, lo que, sumado a la caracterización del homosexual como persona infeliz, acaba reforzando la idea de la superioridad masculina. En esa perspectiva, en las novelas referidas, se impone una visión estereotipada de los géneros que va más allá de la re-producción de la teoría de la identidad homosexual y de los prejuicios de la inferioridad femenina, llegando hasta la sobrevalorización de un modelo de masculinidad.

\section{Apología androcentrista}

En el anterior aparte se hizo referencia a la categorización o constitución de estereotipos por contraste, procedimiento que en el caso de la 
identidad homosexual se realiza con relación a un modelo de masculinidad y con base en una supuesta feminidad o masculinidad fallida atribuida a los homosexuales. De ahí que la caracterización negativa del estereotipo femenino sea fundamental, no solo para reforzar la creencia en la inferioridad de la mujer y del homosexual, sino también para asegurar la idea de la superioridad del hombre heterosexual.

Pero incluso dentro de la relación homosexual, como es presentada en muchas de las novelas, es posible encontrar esa sobrevalorización del estereotipo masculino. En el caso de la relación entre el pervertido y el invertido, este último presenta un mayor número de características negativas, tales como la inseguridad, el oportunismo y/o la ambigüedad. Es lo que ocurre en Bom-Crioulo con Alejo, que cede a las propuestas de la portuguesa y traiciona a Amaro, y en Hombres sin mujer con Andrés, que cede a las presiones de Manuel chiquito y traiciona a Pascasio. En esas novelas, los valores positivos se atribuyen al pervertido, que tiene las cualidades de un hombre: solo Amaro es fuerte, responsable y leal, y en la novela de Montenegro, en la cual todos sufren "la enfermedad del presidio", únicamente el sodomita masculino tiene posibilidades de liderazgo:

El que era toro de verdad, no podía explotar a los infelices por sistema, aunque sí coger lo que le hiciera falta donde quiera que esto estuviera [...] ni andarse con demasiadas precauciones si llevaba algún muchacho al hoyo; ni consentir que un preso, jefe de galera, lo avasallase a título de galones; ni perder la cabeza por un muchacho determinado, aunque sí pelear hasta el fin si le molestaban al que, por el momento, vivía con él -y eso no por el muchacho, al que siempre debía tratar con despego, sino por él mismo-[...] (Montenegro, p. 148).

Pero el contraste entre la visión negativa de la denominada homosexualidad, entendida como masculinidad fallida, y la visión positiva o superior de la masculinidad, entendida como supuesta heterosexualidad, se hace aún más evidente en la oposición activo/pasivo predominante en varias de las novelas de temática homosexual. Así, por ejemplo, en El beso de la mujer araña o en Tengo miedo torero, el carácter racional, pragmático y filantrópico del hombre se opone a la sensibilidad artística, emotiva y egocéntrica del homosexual. En la novela de Puig, Valentín aparece como el sujeto intelectual, crítico, lector de libros de economía política, comprometido con la realidad social y dispuesto a sacrificarse por los demás, mientras que Molina es un sujeto romántico, superficial, que ve filmes estadounidenses y cuya máxima preocupación, por fuera de la salud de su madre, es encontrar el amor de su vida:

- ¿No te cansas de leer?

-No. ¿Cómo te sentís?

-Me está viniendo una depresión bárbara.

-Vamos, vamos, no sea flojo compañero.

- ¿No te cansas de leer con esta luz tan jodida?

-No, ya estoy acostumbrado. Pero de la barriga, ¿cómo te sentís?

-Un poco mejor. Contame qué estás leyendo.

- ¿Cómo te voy a contar?, es filosofía, un libro sobre el poder político.

-Pero algo dirá, ¿no?

-Dice que el hombre honesto no puede abordar el poder político, porque su concepto de la responsabilidad se lo impide.

-Y tiene razón, porque todos los políticos son unos ladrones.

-Para mí es todo lo contrario, quien no actúa políticamente es porque tiene un falso concepto de la responsabilidad. Ante todo mi responsabilidad es que no siga muriendo gente de hambre, y por eso voy a luchar.

-Carne de cañón. Eso es lo que sos.

-Si no entendés nada callate la boca.

-No te gusta que te digan la verdad...

-¡Qué ignorante! Si no sabés no hables.

-Por algo te da tanta rabia...

-¡Basta! Dejame leer.

-Está bien. Algún día que vos estés mal yo te voy a hacer lo mismo. (Puig, 2007, pp. 92-93).

La fantasía romántica de Molina y la utopía política de Valentín favorecen el encuentro sexual en una relación en la cual el primero asume el papel 
de enamorado sacrificado por su amor (del mismo modo que las protagonistas de los filmes que él relata) y el segundo de hombre dispuesto a todo por su causa política. En el texto de Lemebel, en compensación, la relación de "La loca" con Carlos es más maternal; incluso llega a celebrarle una fiesta de cumpleaños con los niños del barrio, y aunque por su juventud el personaje masculino no aparezca tan estereotipado como en Puig, el personaje homosexual tiene todos los rasgos de la feminidad tradicional: apego por lo doméstico, sentido estético, sensibilidad exacerbada y fantasía romántico-sexual, y solo en virtud de esta última es que se hace posible el encuentro corporal. Pero, mientras el contraste sexista en la novela de Puig culmina en tragedia, en el texto de Lemebel se impone la amistad entre los dos personajes, con lo que se consigue relativizar la fuerza de la oposición activo/pasivo y poner en jaque, aunque sea parcialmente, el modelo del sometimiento del homosexual afeminado por el hombre masculino.

A lo mejor soy una loca tonta que confundí las cosas, dijo ella como una niña envolviendo su pena infinita. No te pongas así, no es para tanto. Tú sabes que nunca te voy a olvidar. Y a Carlos también lo embargó la tristeza, y sin saber qué hacer, le tomó sus manos de pájara mustia y las besó con las brasa de sus labios morenos. ¿Cómo podría pagarte todo lo que hiciste por nosotros, y especialmente por mí? Con solo tres palabras. ¿Qué palabras?, dijo él con cierta vergüenza en sus ojos de macho marxista. "Tengo miedo torero". (Lemebel, 2002, p. 211).

La apología del estereotipo masculino continúa vigente en las novelas que retoman elementos de la subcultura gay, aunque el hombre masculino, el denominado "entendido", se asuma como homosexual. Se trata de la diferencia entre "a maricona" y el gay, sintetizada por el personaje de Puig:

$-\succsim Y$ todos los homosexuales son así?

-No, hay otros que se enamoran entre ellos. Yo y mis amigas somos mujer. Esos jueguitos no nos gustan, esas son cosas de homosexuales. Nosotras somos mujeres normales que nos acostamos con hombres. (Puig, 2007, p. 178).
En esos casos la posición de inferioridad la ocupa el homosexual que obedece al modelo tradicional, o sea, aquel que aparece como muy delicado o emocional. Así sucede en Stella Manhattan, donde, desde el comienzo, el personaje afeminado reconoce la superioridad del homosexual masculino:

Um homaço o Vianna, tall and handsome, bonito e pouco latino na sua beleza baby face. Eduardo não acreditou no que via: ele se aproximando com um retrato na mão e lhe perguntando se era o filho do Sérgio. Deu por si e já estava abraçado e comovido e quanto! Grudado naquele Rock Hudson que caminhava pelo meio da estrada dos 50 sem medo dos refletores. (Santiago, 1991, p. 44).

La superioridad del "hombre" (pervertido activo o macho gay) no es solo física, también es comportamental, pero el elogio de lo físico es fundamental en esa apología de la masculinidad. Y no ocurre así únicamente en Stella Manhattan. Sea en el habla del narrador o de algún personaje, es frecuente encontrar elogios al cuerpo y a la actitud viril en casi todas las novelas, asunto que será cuestionado por el revolucionario Valentín en La mujer araña:

-¿Qué es ser un hombre para vos?

-Es muchas cosas, pero para mí... bueno, lo más lindo del hombre es eso, ser lindo, fuerte, pero sin hacer alharaca de fuerza, y que va avanzando seguro. Que camine seguro, como mi mozo, que hable sin miedo, que sepa lo que quiere, adónde va, sin miedo de nada.

-Es una idealización, un tipo así no existe.

-Sí existe, él es así.

-Bueno, dará esa impresión, pero por dentro, en esta sociedad, sin el poder nadie puede ir avanzando seguro, como vos decís. (Puig, 2007, p. 59).

$Y$ es esa seguridad y confianza la que se manifiesta en la fortaleza corporal de Amaro, en la terquedad de Pascasio, en la racionalidad de Valentín, en la imponente presencia de Vianna, en la gravedad de los soldados cubanos, en la levedad de los muchachos cariocas o en la voluptuosidad de los negros pernambucanos. Por cierto, en la obra de Carella, la apología de la virilidad llega, por momentos, a transformarse en fetichismo racial: 
Alguns negros têm o ar de cisnes e usam seus farrapos com uma majestade indescritível. O prazer da côr me domina. Há tantos tons de marrom! Sempre constituem uma surprêsa. Vejo rostos da côr de âmbar que comunicam uma alegria inexplicável. Agora é que estou começando a sentir a côr e compreendo que para muitos estes negros sejam tão desejáveis como mulheres ou talvez mais. (Carella, 1968, p. 194).

Aunque en Orgia la diferencia homosexualheterosexual no sea tan definitiva, en ella aún está presente la inferiorización de afeminados y la sobrevalorización del hombre masculino, a diferencia de lo que sucede en las otras novelas relacionadas con una visión menos identitaria, como Onde andará Dulce Veiga y La virgen de los sicarios, en donde la ausencia de cualquier reflexión o defensa de la identidad homosexual coincide con la ausencia de apología de la masculinidad. Sin embargo, en la obra de Vallejo, el valor de lo masculino es sustituido por el valor de la juventud, condición indispensable de sus posibles o reales amantes; así, el contraste ya no se establece con la feminidad sino con la vejez, de la cual el narradorpersonaje se sabe representante.

$\mathrm{Y}$ a pesar de algunos breves esbozos críticos a la apología de la masculinidad, la tendencia en las novelas leídas es la androlatría, o sea, la valorización del modelo de masculinidad en detrimento de la feminidad atribuida tradicionalmente al homosexual; masculinidad definida básicamente por el elemento corporal y en consonancia con los estereotipos heterosexistas de hombre, de mujer y de homosexual.

Y es en razón de la recurrente presencia de esos estereotipos que queda difícil aceptar la hipótesis de un sentido crítico o de resistencia como característica de la narrativa de temática homosexual. Muy por el contrario, su contenido parece dirigido, no a rescatar del anonimato las prácticas sexuales intermasculinas, ni siquiera a promover los discursos científicos sobre la identidad homosexual, sino a reforzar la idea de la superioridad física y emocional del hombre heterosexual.
Al final, y en virtud de un mecanismo ideológico muy sutil, la inexistente o débil resistencia en esas novelas acaba poniéndose al servicio de un discurso heterosexista o patriarcal que propicia el abuso y la discriminación de minorías como los pobres, los negros, las mujeres e incluso los homosexuales. Es como si el precio de la liberación individual que presupondría la escritura solo fuese posible mediante el sometimiento, especialmente de aquellos que también son minoría. Es como si la forma de liberarse de la marginalización fuese reproducir la marginalidad.

\section{Referencias}

Abreu, C. F. (2007 [1990]). Onde Andará Dulce Veiga? Rio de Janeiro: Agir,

Arenas, R. (1984 [1971]). Arturo, la estrella más brillante. Barcelona: Montesinos. Bersani, L. (1998). Homos (trad. H. Pons). Buenos Aires: Manantial.

Borillo, D. (2001). Homofobia. Barcelona: Bellaterra.

Bosch, E.; Ferrer, V., y Gili, M. (1999). Historia de la misoginia. Barcelona: Anthropos.

Butler, J. (2003). Problemas De Gênero. Feminismo E Subversão Da Identidade (trad., R. Aguiar). Rio de Janeiro: Civilização Brasileira.

Caminha, A. (2003 [1895] ). Bom-Crioulo. São Paulo: Martin Claret.

Carella, T. (1968). Orgia. Diário Primeiro. Rio de Janeiro: José Álvaro Ed.

Foucault, M. (1988 [1976]). História Da Sexualidade 1. A Vontade De Saber (trad. M. T. Da Costa y J. A. Guilhon. Rio de Janeiro: Edições Graal.

Fry, P. y Mcrae, E. (1983). O Que É Homossexualidade? São Paulo: Brasil.

Lemebel, P. (2002 [2001]). Tengo miedo torero. Santiago: Seix Barral.

Montenegro, C. (1938). Hombres sin mujer. México: Massas.

Puig, M. (2007). El beso de la mujer araña. Buenos Aires: Booket.

Santiago, S. (1991 [1985]). Stella Manhattan. Rio de Janeiro: Rocco.

Vallejo, F. (2002 [1994]). La virgen de los sicarios. Buenos Aires: Suma.

Zapata, L. (1972). Las aventuras, desventuras y sueños de Adonis García, el vampiro de la colonia Roma. México: Grijalbo. 